\title{
CHORIONIC VILLUS SAMPLING IN A TERTIARY CARE CENTRE IN SOUTHERN INDIA: A RETROSPECTIVE ANALYTICAL STUDY
}

\author{
Priyanka Pipara1, Manisha Madhai Beck²,Reeta Vijaya Selvi³, Ruby Jose ${ }^{4}$ \\ ${ }^{1}$ Assistant Professor, Department of Obstetrics and Gynaecology, Christian Medical College, Vellore. \\ ${ }^{2}$ Associate Professor, Department of Obstetrics and Gynaecology, Christian Medical College, Vellore. \\ ${ }^{3}$ Associate Professor, Department of Obstetrics and Gynaecology, Christian Medical College, Vellore. \\ ${ }^{4}$ Professor, Department of Obstetrics and Gynaecology, Christian Medical College, Vellore.
}

\begin{abstract}
BACKGROUND: Chorionic villus sampling (CVS) is an invasive diagnostic procedure done in early pregnancy to obtain cells for the prenatal diagnosis of chromosomal and genetic defects.

AIMS: To study the indications, results and complications of pregnancies following transabdominal chorionic villus sampling (CVS). STUDY DESIGN AND SETTINGS: This is a retrospective analytical study on women who had undergone transabdominal CVS in a single unit at the Obstetrics and Gynaecology department, Christian Medical College, Vellore from January 2012 to December 2014. MATERIAL AND METHODS: All pregnant women who underwent CVS for various indications during the specified period were included in the study. The clinical details of the women were retrieved from the hospital database regarding age, domicile, obstetric history, family history, gestation age, indication and outcome of procedure.

RESULTS: Total 67 women had undergone transabdominal CVS during the study period. Out of 67 procedures, tissue retrieval was possible in $64(95.52 \%)$ cases. Out of 64 samples, 2 (2.98\%) were contaminated. Most of the procedures were done between 11-13 weeks gestation. The most common indication for doing the procedure was for chromosomal disorders (39\%). Forty six women (74.19\%) had normal results and 16 (25.80\%) had abnormal results. Of those with abnormal results, 9 (14.51\%) fetuses were affected including 3 with chromosomal abnormalities whereas 7 (11.29\%) had carrier state. Majority of abnormal results were found when indication for the procedure was previous affected child. No woman had vaginal bleeding, leaking or pregnancy loss within 3 weeks of procedure.
\end{abstract}

CONCLUSION: Transabdominal CVS is a safe and reliable outpatient procedure for prenatal diagnosis in early pregnancy and should be considered as procedure of choice. CVS is beneficial in providing early prenatal diagnosis and offering further options of management if pregnancy is affected. In experienced hands miscarriage rate following the procedure is very low.

KEYWORDS: Chorionic Villus Sampling, Prenatal Diagnosis, Chromosome Disorder.

HOW TO CITE THIS ARTICLE: Priyanka Pipara, Manisha Madhai Beck, Reeta Vijaya Selvi, Ruby Jose. "Chorionic Villus Sampling in A Tertiary Care Centre in Southern India: A Retrospective Analytical Study". Journal of Evolution of Medical and Dental Sciences 2015; Vol. 4, Issue 91, November 12; Page: 15630-15632, D0I: 10.14260/jemds/2015/2247.

INTRODUCTION: Chorionic villus sampling (CVS) is the gold standard invasive procedure for first trimester prenatal diagnosis.(1) Trans-abdominal CVS is associated with a lower rate of procedure associated miscarriage than trans-cervical CVS. In experienced hands CVS is a safe procedure with overall foetal loss rate of $0.5-1.5 \% .^{(2)}$

Lau et al concluded that first trimester transabdominal CVS is an accurate and safe invasive prenatal diagnostic procedure. It should be one of the treatment options available to pregnant women who require prenatal genetic diagnosis.(3) Several studies have also found that there was no statistically significant difference between the miscarriage rate following CVS and amniocentesis in recent years.(4-5) The Cochrane Database has also recommended transabdominal CVS as the procedure of first choice before 15 weeks gestation for prenatal diagnosis. $\left.{ }^{6}\right)$

Financial or Other, Competing Interest: None.

Submission 19-10-2015, Peer Review 20-10-2015,

Acceptance 02-11-2015, Published 10-11-2015.

Corresponding Author:

Priyanka Pipara,

Department of Obstetrics and Gynaecology,

Unit 4, Chrisitan Medical College, Vellore.

E-mail: priyankajain07@yahoo.com

DOI:10.14260/jemds/2015/2247.
The detection of genetic or chromosomal abnormality in early pregnancy by CVS provides an option to the parents to have an early termination of severely affected pregnancies. It also enables planning for birth of the affected child so that postnatal care can be optimized.(7)

The aim of our study was to look at the indications, results and complications of pregnancies following transabdominal CVS in a tertiary care centre in southern India. Although there are many similar studies in medical literature, there have been very few studies on CVS in the developing countries.

MATERIALS AND METHODS: We conducted a retrospective descriptive analytical study on all women who had undergone CVS in a single unit at Department of Obstetrics and Gynaecology, Christian Medical College, Vellore from January 2012 to December 2014.

Pregnant women who underwent CVS during the period were included in the study. The clinical details of the women were retrieved from the hospital database. Maternal characteristics such as age and domicile were noted. Clinical details regarding obstetric and family history, indications for the procedure, gestational age at the time of CVS and short term complications were also recorded. 
Pregnancy was dated using the last menstrual period or based on the early pregnancy dating scan if previous menstrual cycles were irregular. A written consent was obtained by the operator doing the procedure from all women undergoing the CVS. In all cases, a preliminary ultrasound scan was done to confirm viable singleton pregnancy, gestational age, placenta location and any other incidental findings that may impact on the procedure. All the procedures were performed via transabdominal route. All women received pre and post procedure counselling by trained genetic counsellor and obstetrician.

CVS was done as a daycare procedure in the antenatal clinic. The procedure was carried out under conscious sedation with women in the supine position. The abdomen was prepped with povidone iodine and draped. About 5-10 ml of $1 \%$ lignocaine was locally infiltrated into the abdominal wall at the site of entry. Under continuous ultrasound guidance, 18 $\mathrm{G}$ long spinal needle was inserted into the abdominal wall, was seen traversing the uterine wall and into the bulk of placental tissue. With the needle in place, the chorionic villi were aspirated by to and fro movement. A three way with extension, attached to the $18 \mathrm{G}$ needle, was used to aspirate the tissue into the $20 \mathrm{cc}$ syringe containing 5 to $10 \mathrm{ml}$ of normal saline. In case of poor yield of the sample, a second attempt was made to retrieve the sample.

The retrieved sample of chorionic tissue was placed into petri dishes containing normal saline and examined under microscope by the operator. Maternal decidua and blood clots were removed and cleaner villi transferred into a fresh petri dish, a process repeated several times, until a clean villi sample was obtained. The final clean samples were weighed before sending it to the lab.

Following the procedure, scan was done to check fetal heart beat and look for any subchorionic haematoma. The patient was allowed to go home after two to three hours of the procedure. No prophylactic antibiotics were used. Rhesus prophylaxis with anti-D immunoglobulin was given following each procedure in Rh-negative mothers.Follow-up was done after three weeks. All patients were interviewed at the time of follow up for vaginal bleeding, leaking or miscarriage.

RESULTS: The study included total 67 women who underwent CVS procedure. All of them had singleton viable pregnancies, there were no multiple gestations in the study. The common indications for the procedure are shown in Figure 1. The most common indication for doing the procedure was for chromosomal disorders. Out of these 12 procedures (50\%) were done in women with previous baby having chromosomal disorders; eight (33.33\%) were carried out for suspected fetal chromosomal abnormality based on scan findings and four (16.6\%) were done because of high risk on combined first trimester screen for aneuploidy. Ten (16\%) women underwent CVS for miscellaneous disorders (Figure1). They had previous child affected with cystic fibrosis, neurofibromatosis, congenital adrenal hyperplasia, fragile $\mathrm{X}$ syndrome and Larsen syndrome.

Demographic characteristics of patients who underwent CVS are shown in table 1. Most of the women (34.32\%) were between 25 to 30 years of age group while collectively those below 35 years were in the majority (94.03\%). Most of the procedures were done between 11-13 weeks of gestation $(59.7 \%)$, while $4(5.97 \%)$ cases were done after 17 weeks of gestation. Approximately half of the patients were from outside Tamil Nadu as most of them were referred cases.

Out of total 67 procedures, tissue retrieval was possible in $64(95.52 \%)$ cases. Of 64 cases, two $(2.98 \%)$ samples were contaminated (Table 2). Indications and results of the procedure are shown in table 3 . Out of the 62 samples, 46 had normal results and 16 had abnormal results. Of the 16 with abnormal results, 9 foetuses were affected, including 3 with chromosomal abnormalities, whereas 7 had carrier state. Majority of abnormal results were found when indication for the procedure was previous affected child. No women had vaginal bleeding, haematoma formation, leaking or pregnancy loss within 3 weeks of procedure.

DISCUSSION: Chorionic villus sampling has emerged as the only safe invasive prenatal diagnostic procedure in the first trimester. Majority of invasive prenatal diagnostic procedures in the developed world are performed for individuals deemed to be at high risk for Down's syndrome.(2) In our study, in contrast only $38.7 \%$ cases were done to detect chromosomal anomalies and rest were done to detect single gene disorders like metabolic disorders, haematological disorders and others.

Majority (60\%) of the CVS procedures in our study were performed between 11-13 weeks of gestation similar to other studies (7). The overall success rate in obtaining a sample without maternal contamination by transabdominal CVS was $92.53 \%$. Ajayi et al had reported a success rate of $98 \%$ but their study included both transcervical and transabdominal approach(8). Transabdominal CVS done by Abeera et al on 200 patients showed $100 \%$ success. $\left.{ }^{2}\right)$

All three cases in which procedure was unsuccessful in our study had history of one or more caesarean sections. However, we did not find high body mass index as a limiting factor in obtaining specimen. In our study, practically all positions of placenta were sampled without much difficulty via the transabdominal route. This is in contrast to the general opinion that horizontally placed posterior placenta are better sampled with the transcervical approach.(1)

The largest meta-analysis of 29 studies for complications with transabdominal CVS was performed by Mujezinovic and Alfirevic.(9) The aim of study was to compile a systemic review of complications related to CVS and to provide a benchmark data for counselling and performance and assessment. Pregnancy losses were classified as within 14 days of procedure; within 24 weeks of gestation and total. The benchmark was $0.7 \%, 1.3 \%$ and $2 \%$. Abeera et al have reported haematoma formation in $1.5 \%$ cases.(2) In our study, there were no miscarriages or haematoma formation following three weeks of the procedure. As most of our cases were referred from other parts of India and occasionally overseas, long term follow up could not be done.

Limb reduction defects have been linked to early CVS before 10 weeks of pregnancy but this was not an issue in our study as most of the procedures were carried out between 1113 weeks.(10) Most women had mild to moderate pain following the procedure which settled with Non steroidal antiinflammatory drugs. 
CONCLUSION: Transabdominal CVS is a safe and reliable outpatient procedure for prenatal diagnosis in early pregnancy and should be considered as procedure of choice. In experienced hands, the miscarriage rate is very low and, thus, can be safely offered as an alternative to amniocentesis for prenatal diagnosis. CVS is beneficial in providing early prenatal diagnosis and offering further options of management if pregnancy is affected.

\section{REFERENCES:}

1. Blumenfeld YJ, Chueh J. Chorionic villus sampling: technique and training. Curr Opin Obstet Gynecol. 2010 Apr;22(2):146-51.

2. Choudry A, Masood S, Ahmed S. Feasibility and safety of transabdominal chorionic villus sampling. J Ayub Med Coll Abbottabad JAMC. 2012 Mar;24(1):38-43.

3. Lau KT, Leung YT, Fung YT, Chan LW, Sahota DS, Leung NT. [Outcome of 1,355 consecutive transabdominal chorionic villus samplings in 1,351 patients]. Chin Med J (Engl). 2005 Oct 20;118(20):1675-81.

4. Caughey AB, Hopkins LM, Norton ME. Chorionic villus sampling compared with amniocentesis and the difference in the rate of pregnancy loss. Obstet Gynecol. 2006 Sep;108(3 Pt 1):612-6.
5. American College of Obstetricians and Gynecologists. ACOG Practice Bulletin No. 88, December 2007. Invasive prenatal testing for aneuploidy. Obstet Gynecol. 2007 Dec;110(6):1459-67.

6. Alfirevic Z, Mujezinovic F, Sundberg K. Amniocentesis and chorionic villus sampling for prenatal diagnosis. Cochrane Database of Systematic Reviews [Internet]. John Wiley \& Sons, Ltd; 1996 [cited 2015 May 28]. Available

from:http://onlinelibrary.wiley.com/doi/10.1002/1465 1858.CD003252/abstract

7. Oloyede 0 , Olaide A, Onyinye N. Clinical and laboratory experience of chorionic villous sampling in Nigeria. Niger J Clin Pract. 2014;17(4):511.

8. Ajayi GO. Chorionic villus sampling: analysis of the first 350 singleton pregnancies by a single operator. Clin Exp Obstet Gynecol. 2009;36(4):251-3.

9. Mujezinovic F, Alfirevic Z. Procedure-related complications of amniocentesis and chorionic villous sampling: a systematic review. Obstet Gynecol. 2007 Sep;110(3):687-94.

10. Tabor A, Alfirevic Z. Update on procedure-related risks for prenatal diagnosis techniques. Fetal Diagn Ther. 2010;27(1):1-7.

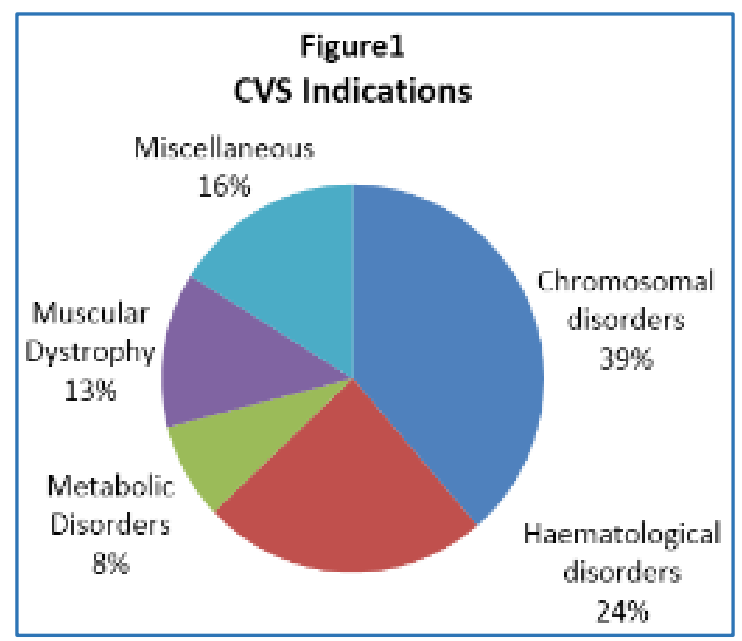

Fig.1: Indications of trasabdominal CVS

\begin{tabular}{|c|c|c|}
\hline Parameter & $\begin{array}{c}\text { Number } \\
(n=67)\end{array}$ & Percentage \\
\hline \multicolumn{3}{|l|}{ Age } \\
\hline $21-25$ & 21 & 31.34 \\
\hline $26-30$ & 23 & 34.32 \\
\hline $31-35$ & 19 & 28.35 \\
\hline $36-40$ & 4 & 5.97 \\
\hline \multicolumn{3}{|l|}{ Gestation Age (weeks) } \\
\hline $11-13$ & 40 & 59.70 \\
\hline$>13-17$ & 23 & 34.32 \\
\hline$>17$ & 4 & 5.97 \\
\hline \multicolumn{3}{|l|}{ Place } \\
\hline Tamilnadu & 33 & 49 \\
\hline Rest of South India & 13 & 20 \\
\hline North India & 15 & 22 \\
\hline Overseas & 6 & 9 \\
\hline \multicolumn{3}{|c|}{ Table 1: Maternal Characteristics } \\
\hline
\end{tabular}

\begin{tabular}{|c|c|c|}
\hline Parameter & Number & Percentage \\
\hline Successful & 62 & 92.53 \\
\hline Failed & 3 & 4.47 \\
\hline Sample Contaminated & 2 & 2.98 \\
\hline \multicolumn{2}{|c|}{ Table 2: Outcome of Procedure } \\
\hline
\end{tabular}

\begin{tabular}{|c|c|c|c|}
\hline $\begin{array}{c}\text { Indications } \\
\mathbf{N}=\mathbf{6 2}\end{array}$ & Affected & Carrier & Normal \\
\hline $\begin{array}{c}\text { Chromosomal } \\
\text { Disorder } \\
\mathrm{n}=24(38.70 \%)\end{array}$ & $3(12.50 \%)$ & - & $\begin{array}{c}21 \\
(87.50 \%)\end{array}$ \\
\hline $\begin{array}{c}\text { Haematological } \\
\text { Disorder } \\
\mathrm{n}=15(19 \%)\end{array}$ & $1(11.11 \%)$ & $4(44.44 \%)$ & $\begin{array}{c}4 \\
(44.44 \%)\end{array}$ \\
\hline $\begin{array}{c}\text { Thalassemia } \mathrm{n}=9 \\
(60 \%)\end{array}$ & $2(50 \%)$ & $1(25 \%)$ \\
$\begin{array}{c}\text { Haemophilia } \mathrm{n}=4 \\
(26.66 \%)\end{array}$ & $1(25 \%)$ & $0(0 \%)$ & $2(100 \%)$ \\
$\begin{array}{c}\text { Haemophagocytosis } \\
\mathrm{n}=2(13.33 \%)\end{array}$ & $0(0 \%)$ & $1(20 \%)$ & $3(60 \%)$ \\
\hline $\begin{array}{c}\text { Metabolic disorder } \\
\mathrm{n}=5(8.06 \%)\end{array}$ & $1(20 \%)$ & $0(0 \%)$ & $8(100 \%)$ \\
\hline $\begin{array}{c}\text { Muscular Dystrophy } \\
\mathrm{n}=8(12.90 \%)\end{array}$ & $0(0 \%)$ & $0(0 \%)$ & $7(70 \%)$ \\
\hline $\begin{array}{c}\text { Miscellaneous } \\
\text { Disorders } \\
\mathrm{n}=10(16.12 \%)\end{array}$ & $3(30 \%)$ & & \\
\hline
\end{tabular}

Table 3: Indications and Results of the Procedure 